\title{
Hydroxychloroquine and azithromycin as potential treatments for COVID-19; clinical status impacts the outcome
}

\author{
Malek Okour ${ }^{1}$ (D) $\cdot$ Mahmoud Al-Kofahi ${ }^{2} \cdot$ Daren Austin $^{3}$
}

Received: 27 April 2020 / Accepted: 4 May 2020/Published online: 13 May 2020

(C) Springer Science+Business Media, LLC, part of Springer Nature 2020

In March 2020, hydroxychloroquine (HCQ) and azithromycin were tested as potential treatments for COVID19 pandemic, in an open label non-randomized clinical trial [1]. Data were collected from 36 confirmed COVID-19 patients after receiving no treatment $(\mathrm{n}=16)$ or $200 \mathrm{mg}$ q8h of HCQ with $(n=6)$ or without $(n=14)$ azithromycin depending on clinical status. Collected data over six days included one HCQ concentration per patient; respiratory viral loads (PCR assay); azithromycin co-treatment; and clinical status among other variables.

Using observed HCQ concentrations and basic pharmacokinetic equations, it was possible to calculate missing concentrations at all days for all patients (Supplementary Fig. S1). Daily viral load, presented as PCR threshold cycle (CT), was converted into a dichotomous variable (positivePCR or negative-PCR). A logistic regression evaluated whether HCQ concentrations, azithromycin co-treatment (yes/no), clinical status (asymptomatic, upper or lower respiratory tract infection [URTI or LRTI]), time (day $0-6$ ), and other covariates (age, sex) were associated with response (positive-PCR outcome).

Electronic supplementary material The online version of this article (doi:https://doi.org/10.1007/s10928-020-09689-x) contains supplementary material, which is available to authorized users.

Malek Okour

malek.x.okour@gsk.com

Mahmoud Al-Kofahi

malkofah@umn.edu

Daren Austin

daren.j.austin@gsk.com

1 GlaxoSmithKline, Collegeville, PA, USA

2 College of Pharmacy, University of Minnesota, Minneapolis, MN, USA

3 GlaxoSmithKline, London, UK
Model evaluation and selection was performed based on statistical significance ( $\mathrm{p}$-value $\leq 0.05$ ) and diagnostic plots (Supplementary Figs. S2, S3). The final model contained HCQ log-concentrations ( $\mathrm{ng} / \mathrm{ml}$ ), azithromycin cotreatment, clinical status, and day as statistically significant covariates (Figs. 1 and S4).

Results showed that the odds of positive-PCR decrease by $53 \%$ for each unit increase in HCQ log-concentration. Similarly, the odds decrease by $61 \%$, and by $12 \%$ for each day increase, and for azithromycin co-treatment, respectively. Whereas the odds of positive-PCR increase by 99.4 folds and 212 folds for having URTI and LRTI versus being asymptomatic subject.

Using the model, minimum HCQ concentrations to achieve $>50 \%$ probability of negative-PCR on day 3 were calculated, with or without azithromycin, for the clinical statuses. A minimum HCQ concentration $(\mathrm{ng} / \mathrm{ml})$ of 8103 (without azithromycin) and 282 (with azithromycin) are needed in subjects with LRTI. A minimum HCQ concentration $(\mathrm{ng} / \mathrm{ml}$ ) of 2441 (without azithromycin) and 83.9 (with azithromycin) are needed in subjects with URTI. Asymptomatic patients require minimal HCQ concentrations $(<2 \mathrm{ng} / \mathrm{ml})$ regardless of azithromycin co-treatment.

Next, HCQ population PK model [2] was used to simulate dosing regimens needed to achieve targeted HCQ concentrations. Simulations showed that when HCQ is coadministered with azithromycin, a loading dose is critical in rapid achievement of targeted concentrations. The suggested dosing regimen for HCQ (with azithromycin), is $600 \mathrm{mg}$ at 0 and 400 at $8 \mathrm{~h}$ followed by $200 \mathrm{mg}$ q8h (Supplementary Fig. S5). When HCQ is administered without azithromycin, no safe and suitable HCQ dose can achieve targeted concentrations in LRTI and URTI patients (Supplementary Fig. S6).

The analysis confirms that co-treatment of COVID-19 with HCQ and azithromycin increases the probability of negative-PCR in patients. It also shows that clinical status affects the treatment outcome. This analysis is based on 


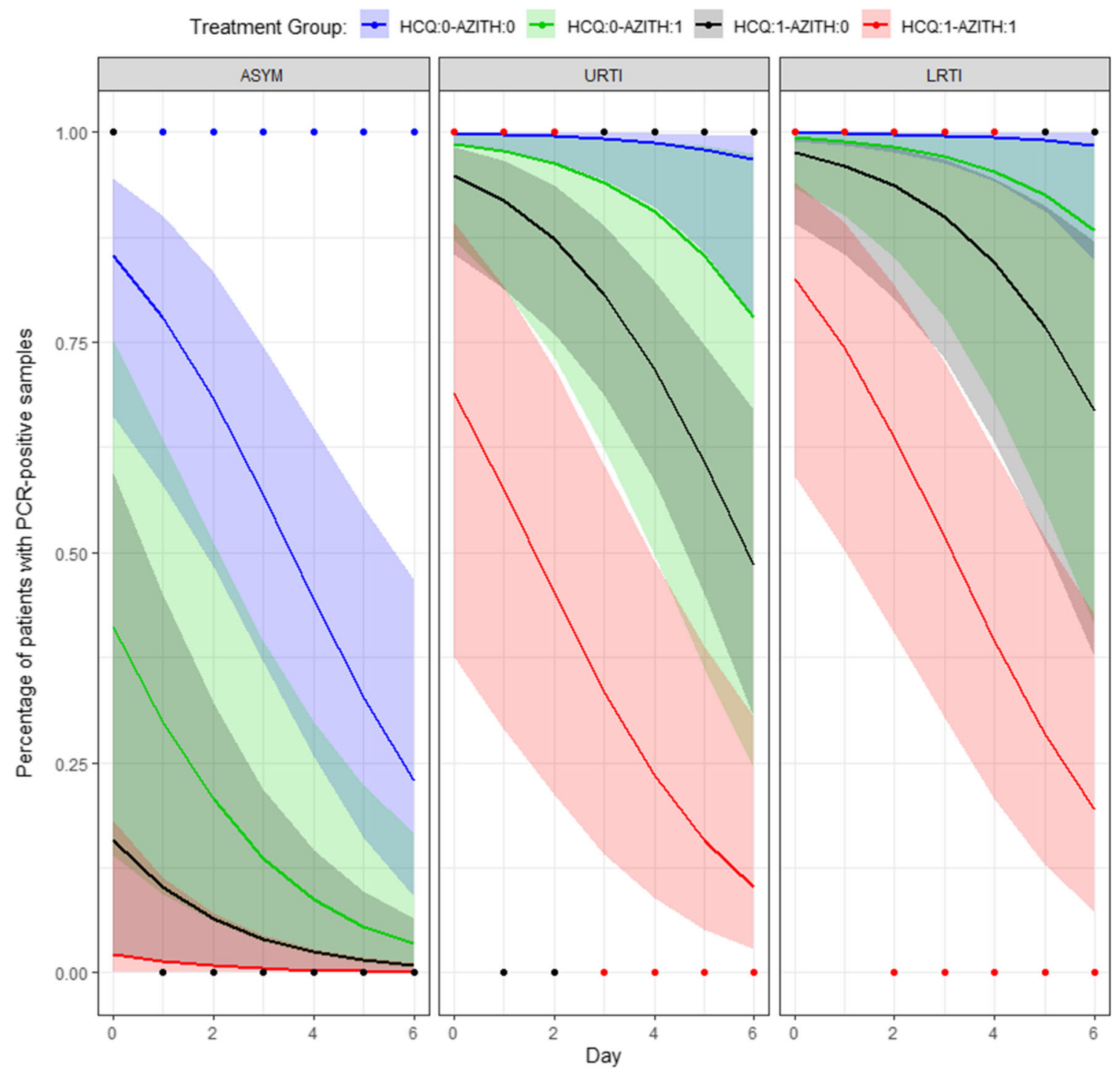

Fig. 1 Predicted Probability of Positive-PCR across treatment days at average hydroxychloroquine concentration. *Points are observed data reported in Gautret et al. study. Solid lines and shaded areas are predicted probability with $95 \%$ confidence interval. ASYM

limited published data; therefore, the results should be interpreted with caution. The analysis cannot inform on the eventual patient outcome, it only evaluates time to undetectable viral load. Further clinical evaluation of HCQ and azithromycin are merited. Benefit-risk profile needs to be taken into account due to known adverse events associated with HCQ and azithromycin.

\section{References}

1. Gautret P, Lagier JC, Parola P, Hoang VT, Meddeb L, Mailhe M et al (2020) Hydroxychloroquine and azithromycin as a treatment asymptomatic, AZITH azithromycin co-treatment, $H C Q$ hydroxychloroquine, URTI upper respiratory tract infection, LRTI lower respiratory tract infection; Legend: 0 means the respective drug is not taken while 1 means the respective drug is taken

of COVID-19: results of an open-label non-randomized clinical trial. Int J Antimicrob Agents 20:20. https://doi.org/10.1016/j. ijantimicag.2020.105949:105949

2. Lim HS, Im JS, Cho JY, Bae KS, Klein TA, Yeom JS, Kim TS, Choi JS, Jang IJ, Park JW (2009) Pharmacokinetics of hydroxychloroquine and its clinical implications in chemoprophylaxis against malaria caused by Plasmodium vivax. Antimicrob Agents Chemother 53(4):1468-1475

Publisher's Note Springer Nature remains neutral with regard to jurisdictional claims in published maps and institutional affiliations. 